\title{
Structural requirement and stereospecificity of tetrahydroquinolines as potent ecdysone agonists.
}

\section{$\operatorname{AUTHOR}(S):$}

Kitamura, Seiya; Harada, Toshiyuki; Hiramatsu, Hajime; Shimizu, Ryo; Miyagawa, Hisashi; Nakagawa, Yoshiaki

\section{CITATION:}

Kitamura, Seiya ...[et al]. Structural requirement and stereospecificity of

tetrahydroquinolines as potent ecdysone agonists.. Bioorganic \& medicinal chemistry letters 2014, 24(7): 1715-1718

ISSUE DATE:

2014-04-01

URL:

http://hdl.handle.net/2433/187052

\section{RIGHT:}

C 2014 Elsevier Ltd.; この論文は出版社版でありません。引用の際には 出版社版をご確認ご利用ください。; This is not the published version. Please cite only the published version. 
Manuscript prepared for publication in Bioorganic Medicinal Chemistry Letters

Structural requirement and stereospecifity of tetrahydroquinolines as potent ecdysone agonists

Seiya Kitamura ${ }^{\mathrm{a}}$, Toshiyuki Harada ${ }^{\mathrm{a}}$, Hajime Hiramatsu ${ }^{\mathrm{b}}$, Ryo Shimizu ${ }^{\mathrm{b}}$, Hisashi Miyagawa $^{\mathrm{a}}$, Yoshiaki Nakagawa ${ }^{\mathrm{a} *}$

${ }^{\text {a }}$ Graduate School of Agriculture, Kyoto University, Kyoto 606-8502, Japan

${ }^{\mathrm{b}}$ Mitsubishi Tanabe Pharma Corporation, Kashima 3-16-89, Yodogawa, Osaka 532-8505, Japan

Corresponding author

Dr. Yoshiaki Nakagawa

Graduate School of Agriculture

Kyoto University

Kyoto 606-8502, Japan

Tel: +81-75-753-6117

Fax: +81-75-753-6128

E-mail: naka@kais.kyoto-u.ac.jp 


\begin{abstract}
Tetrahydroquinoline (THQ)-type compounds are a class of potential larvicides against mosquitoes. The structure-activity relationships (SAR) of these compounds were previously investigated (Sumith et al., Bioorg. Med. Chem. Lett., 2003, 13, 1943-1946), and one the of cis-forms (with respect to the configrations of 2-methyl and 4-anilino substitutions on the THQ basic structure) was stereoselectively synthesized. However, the absolute configrations of $\mathrm{C} 2$ and $\mathrm{C} 4$ were not determined. In this study, four THQ-type compounds with cis configrations were synthesized, and two were submitted for X-ray crystal structure analysis. This analysis demonstrated that two enantiomers are packed into the crystal form. We synthesized the cis-form of the fluorinated THQ compound, according to the published method, and the enantiomers were separated via chiral HPLC. The absolute configurations of the enantiomers were determined by X-ray crystallography. Each of the enantiomers was tested for activity against mosquito larvae in vivo and competetive binding to the ecdysone receptor in vitro. Compared to the $(2 \mathrm{~S}, 4 \mathrm{R})$ enantiomer, the $(2 R$, 4S) enantiomer showed 55 times higher activity in the mosquito larvicidal assay, and 36 times higher activity in the competetive receptor binding assay.
\end{abstract}

Keywords: tetrahydroquinoline; ecdysone; stereospecificity; mosquito; larvicide 
Two major classes of peripheral insect hormones, juvenile hormones (JHs) and molting hormones regulate insect growth. The principal molting hormone of insects is 20-hydroxyecdysone (20E). ${ }^{1} 20 \mathrm{E}$ and its agonist_bind to ecdysone receptors (EcRs) in collaboration with the heterodimeric partner, ultraspiracle (USP), and transactivate molting-related genes. ${ }^{2}$ In a few arthropods, other steroid compounds such as ponasterone A (PonA), makisterone A, and ecdysone act as molting hormones. ${ }^{3}$ To date, the primary sequences of EcRs and USPs have been identified in various insects. ${ }^{3,4}$ Three-dimensional structures of the ligand binding domains of EcRs with ponasterone A as the ligand molecule were solved by X-ray crystal analysis in three insects: Heliothis virescens, ${ }^{5}$ Bemicia tabacii, ${ }^{6}$ and Tolibolium castaneum. ${ }^{7}$ The ligand-binding characteristics of 20E, which are similar to that of PonA, were also solved in $H$. virescens. ${ }^{8}$ The binding sites of non-steroidal ecdysone agonists for diacylhydrazine (DAH; BYI06830) ${ }^{5}$ and two imidazole type compounds, BYI08346 and PDB 3IXP, ${ }^{9}$ were also solved by X-ray analysis. However, these structures differ from those of PonA and 20E.

Compounds that regulate insect molting and metamorphosis are known as insect growth regulators (IGRs) or more recently as insect growth disruptors (IGDs), and some of these compounds are used as insecticides in the agricultural field. ${ }^{10}$ IGDs can be classified into three major categories, juvenile hormone agonists, chitin synthesis inhibitors and molting hormone agonists. Among molting hormone agonists, five diacylhydrazine (DAH)-type compounds (tebufenozide, methoxyfenozide, chlomafenozide, fufenozide, and halofenozide) are used currently. Most of DAH-type compounds are selectively toxic to Lepidoptera, except for halofenozide, which is registered to control both Lepidoptera and 
Coleoptera. However, the binding affinity of halofenozide to coleopteran receptors is not stronger than that of other lepidopteran-specific DAHs. ${ }^{11}$

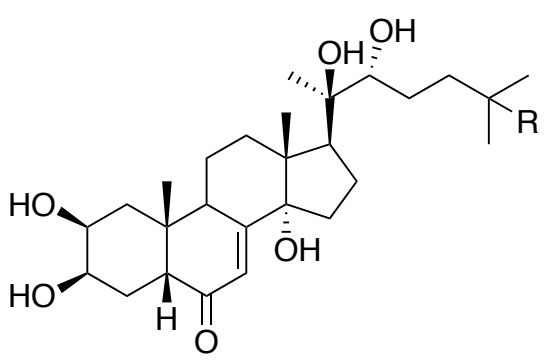

$\mathrm{R}=\mathrm{OH}$ : 20-Hydroxyecdysone (20E)

$\mathrm{R}=\mathrm{H}$ : Ponasterone $\mathrm{A}$ (PonA)

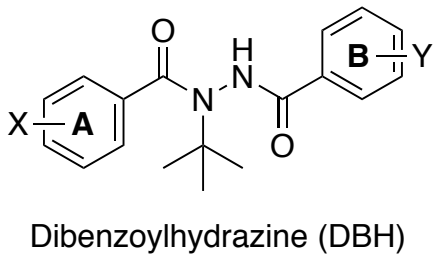

$\mathrm{X}=\mathrm{Y}=\mathrm{H}: \mathrm{RH} 5849$

$\mathrm{X}=3,5-\left(\mathrm{CH}_{3}\right)_{2}, \mathrm{Y}=4-\mathrm{Et}$ : Tebufenozide

$\mathrm{X}=\mathrm{H}, \mathrm{Y}-4-\mathrm{Cl}$ : Halofenozide<smiles>[X]c1ccc(NC2CC(C)N(C(=O)c3c[Y]ccc3)c3ccc([X])cc32)cc1</smiles>

Tetrahydroquinoline (THQ)

Fig. 1. Structures of ecdysone agonists

The high degree of specificity of DAHs against Lepidoptera triggered a search for new ecdysone agonists, in both random and rational manners. Although novel non-steroidal ecdysone agonists have been reported, none of these has been used commercially. ${ }^{12}$ Among new ecdysone agonists, tetrahydroquinoline (THQ)-type compounds are reported to be dipteran-specific, ${ }^{13}$ particularly to the mosquito EcR. ${ }^{14}$ These compounds have a unique specificity toward mosquitos, which may offer a more selective and environmentally friendly pest-management option. Therefore, THQs are promising leads to develop into larvicides for mosquito control. A previous structure-activity relationship (SAR) study of THQs focused on the optimization of the substituents $\mathrm{X}$ and $\mathrm{Y}$, and showed that a fluorinated THQ (X=F, Y=4-Cl: THQ in Fig. 1) had the highest ecdysone agonistic activity for the Aedes aegypti EcR among the 35 compounds tested. ${ }^{13}$ We initially synthesized a 
few THQ analogs according to the published method, ${ }^{13,15}$ and compared the binding and insecticidal activity of the analogs with the reported activities as shown in Table 1 . We also reported that compounds lacking the benzene ring of the quinoline structure and the aniline moiety, as well as the trans isomer of the 2,4-positions of quinoline moiety were inactive. ${ }^{15}$ According to Smith and co-workers ${ }^{13}$, one of two possible $c i s$-stereoisomers $(2 R$, $4 S$ ) was obtained as a final product by the Doebner-von Miller reaction. However, convincing data regarding the stereochemistry of this compound was not reported. In the present study, we observed that Smith's synthesis method did not yield a stereochemically pure intermediate. Instead, it yields a racemic mixture via Doebner-von Miller reaction. We therefore hypothesized that the THQ reaction mixture prepared by this method also contained the $(2 S, 4 R)$ cis enantiomer. In our preliminary study, we analyzed the X-ray crystal structure to determine the absolute configuration of the cis isomers of compounds $\mathbf{1}$ (CCDC 984528: Supplement Table 1S) and 2 (CCDC 984529: Supplement Table 1S), in which the two enantiomers are packed, respectively. Smith and co-workers reported the stereochemistry of THQs based on H-NMR analysis, which is difficult ${ }^{13,16}$ without using special chiral analysis techniques such as chiral NMR solvent.

We then asked which enantiomer was biologically active. To determine this, the $c i s$ product of compound $4(\mathrm{Y}=4-\mathrm{Br})$ containing two enantiomers [4a $(2 S, 4 R)$ and $\mathbf{4 b}(2 R, 4 S)]$ was prepared according to the reported procedure ${ }^{21}$, and analyzed by chiral HPLC. ${ }^{22} \mathrm{~A}$ baseline separation of the two enantiomers was achieved with an amylose-based chiral HPLC column, ${ }^{17}$ packed with a silica gel bound to tris (3,5-dimethylphenylcarbamate) derivatives of amylose and eluted with hexane/ethanol (90/10, v/v). The enantiomer excess 
was determined by chiral HPLC and found to be $>99 \%$. Each fraction was recrystallized from hexane-ethyl acetate and the absolute configurations were determined by X-ray crystallography as shown in Fig. 2 with their chemical structures. ${ }^{23}$<smiles>C[C@@H]1C[C@@H](Nc2ccc(F)cc2)c2cc(F)ccc2N1C(=O)c1ccc(Br)cc1</smiles>

4a $(2 S, 4 R)$
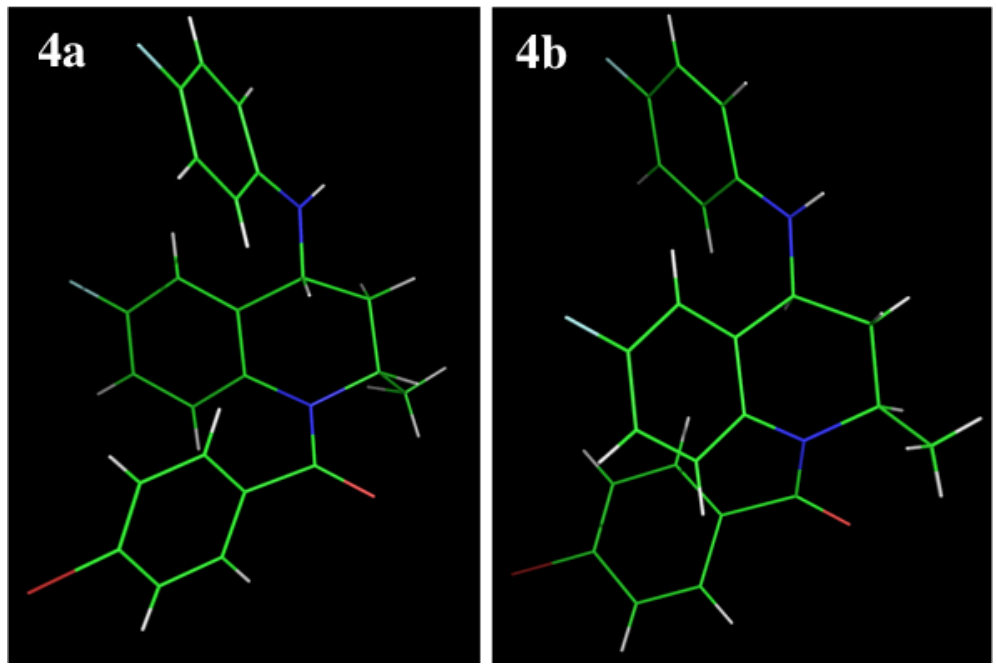

Fig. 2. X-ray structures of enantiomer $\mathbf{4 a}$ and $\mathbf{4 b}$.

Crystal data and the data collection parameters for compounds $\mathbf{4 a}$ (CCDC 984530) and $\mathbf{4 b}$ (CCDC 984531) are listed in Table 1. 
Table 1. X-ray crystallographic data for enantiomers $\mathbf{4 a}$ and $\mathbf{4 b}$

\begin{tabular}{ccc}
\hline & \multicolumn{2}{c}{ Retension time (HPLC) } \\
\cline { 2 - 3 } & $\mathbf{4 . 3} \mathbf{~ m i n}$ & $\mathbf{5 . 8} \mathbf{~ m i n}$ \\
\hline Empirical formula & $\mathrm{C}_{23} \mathrm{H}_{19} \mathrm{BrF}_{2} \mathrm{~N}_{2} \mathrm{O}$ & $\mathrm{C}_{23} \mathrm{H}_{19} \mathrm{BrF}_{2} \mathrm{~N}_{2} \mathrm{O}$ \\
Formula weight & 457.32 & 457.32 \\
Crystal system & orthorhombic & orthorhombic \\
Space group & $\mathrm{P} 2{ }_{1} 2_{1} 2_{1}(\# 19)$ & $\mathrm{P} 2_{1} 2_{1} 2_{1}(\# 19)$ \\
a $(\AA)$ & $7.726(1)$ & $7.7240(2)$ \\
$\mathrm{b}(\AA)$ & $11.425(1)$ & $11.423(3)$ \\
$\mathrm{c}(\AA)$ & $23.284(2)$ & $23.288(5)$ \\
$V\left(\AA \AA^{3}\right)$ & $2055.4(3)$ & $2054.8(8)$ \\
$Z, D_{\text {calc }}\left(\mathrm{g} / \mathrm{cm}^{3}\right)$ & $4,1.478$ & $4,1.478$ \\
$F(000)$ & 928.00 & 928.00 \\
$\mu\left(\mathrm{Cu} \mathrm{K \alpha}\left(\mathrm{mm}^{-1}\right)\right.$ & 3.024 & 3.025 \\
$T(\mathrm{~K})$ & 243 & 243 \\
no. obsd & 3506 & 3338 \\
$(I>2.00 \sigma(I))$ & & \\
no. parameters & 265 & 265 \\
$R R_{1}, \mathrm{w} R_{2}$ & $0.040,0.156$ & $0.043,0.145$ \\
Flack parameter & $0.01(2)$ & $0.01(2)$ \\
GOF & 1.300 & 1.031 \\
\hline
\end{tabular}

The structure-activity relationships for compounds $\mathbf{1}-\mathbf{3}$ were consistent with the previously reported structure-activity relationships (SAR). ${ }^{13}$ The newly synthesized compound $\mathbf{4}$ is three times more toxic against mosquitoes than compound $\mathbf{3}$, as shown in Table 2. The cis- $(2 R, 4 S)$ enantiomer (4b) showed 55 times higher larvicidal activity against mosquito Culex pipiens pallens than the cis- $(2 S, 4 R)$ enantiomer (4a). ${ }^{24}$ The concentration-response relationships for the larvicidal activity of these enantiomers are shown in Fig. 3. Consistently, the active compound $\mathbf{4 b}$ had approximately two times higher larvicidal activity than the racemic compound 4. 


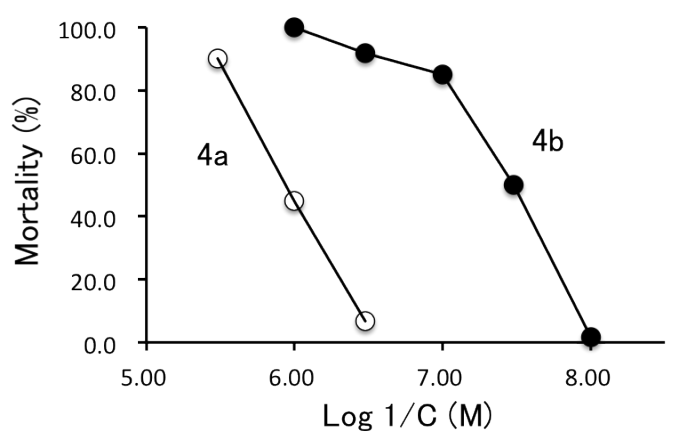

Fig. 3. Concentration-response relationships for $\mathbf{4 a}(\bigcirc)$ and $\mathbf{4 b}(\mathbf{O})$ against the survival of mosquito larvae.

The EcR-THQ interaction was then investigated to understand the specific larvicidal activity of these enantiomers in vitro. We performed a competitive binding assay using $\left[{ }^{3} \mathrm{H}\right]$ PonA as a radioactive ligand for Aedes albopictus (AeAl) cell (NIAS-AeAl-2) binding. ${ }^{18,19,25}$ The results revealed that $\mathbf{4 b}$ has a binding affinity for EcR that is 36 times more potent than 4a (Table 2). These data indicate that differences in binding affinity toward EcR account for the observed larvicidal activity.

Table 2. In vivo and in vitro biological activities of ecdysone agonists ${ }^{\mathrm{a}}$

\begin{tabular}{|c|c|c|c|c|}
\hline \multicolumn{3}{|c|}{ Compounds } & \multirow{3}{*}{$\begin{array}{l}\text { Larvicidal activity } \\
\mathrm{pLC}_{50}(\mathrm{M})\end{array}$} & \multirow{2}{*}{$\begin{array}{l}\text { Binding activity } \\
\operatorname{pIC}_{50}(\mathrm{M})\end{array}$} \\
\hline No. & \multicolumn{2}{|c|}{$(\mathrm{THQ})^{\mathrm{b}}$} & & \\
\hline & $X$ & $\mathrm{Y}$ & & \\
\hline 1 & $\mathrm{CH}_{3}$ & $4-\mathrm{CH} 3$ & 5.33 & n.d. ${ }^{\mathrm{c}}$ \\
\hline 2 & $\mathrm{CH}_{3}$ & $4-\mathrm{Cl}$ & 5.38 & 5.93 \\
\hline 3 & $\mathrm{~F}$ & $4-\mathrm{Cl}$ & 6.52 & n.d. \\
\hline 4 & $\mathrm{~F}$ & $4-\mathrm{Br}$ & $6.92^{\mathrm{d}}$ & $6.65 \pm 0.13(n=3)$ \\
\hline $4 a$ & $\mathrm{~F}$ & $4-\mathrm{Br}$ & $5.65 \pm 0.42(n=2)$ & $5.70 \pm 0.16(n=2)$ \\
\hline $4 b$ & $\mathrm{~F}$ & $4-\mathrm{Br}$ & $7.40 \pm 0.04(n=2)$ & $7.26 \pm 0.04(\mathrm{n}=2)$ \\
\hline \multicolumn{3}{|c|}{ Ponasterone A } & n.d. & $9.01 \pm 0.01(n=2)$ \\
\hline \multicolumn{3}{|c|}{ Tebufenozide } & n.d. & $7.12 \pm 0.03(n=2)$ \\
\hline
\end{tabular}


${ }^{\text {a }}$ Mean values with standard deviation. Number of experiments.

${ }^{\mathrm{b}}$ Basic structure is shown in Fig. 1.

${ }^{\mathrm{c}}$ n.d. not determined.

${ }^{\mathrm{d}}$ The trans-type compound $(2 S, 4 S+2 S, 4 S)$ is inactive $(<4.52)$.

Figure 4 shows a summary of the SARs of THQs. The methyl group in position 2 is required to be in the $2 R$ conformation, and the methyl substituent can be replaced with hydrogen. Conversely, the $2 S$ methyl substituent leads to lower activity. This implies that the $2 S$ methyl group has a steric collision with the receptor, whereas the $2 R$ methyl group and the hydrogen do not. The aniline moiety in position 4 is essential for the larvicidal activity as reported previously ${ }^{15}$ and the $4 S$ chiral conformation is also critical for activity. The phenyl group on tetrahydroquinoline ring is also required for activity, but the substituent $\mathrm{R}_{3}$ is not essential. ${ }^{13}$ The larvicidal potency was improved approximately 3 fold by changing $\mathrm{R}_{4}$ from 4-chloro to 4-bromo, which can be further optimized in future studies. This SAR summary provides valuable information for the molecular design of novel ecdysone agonists.

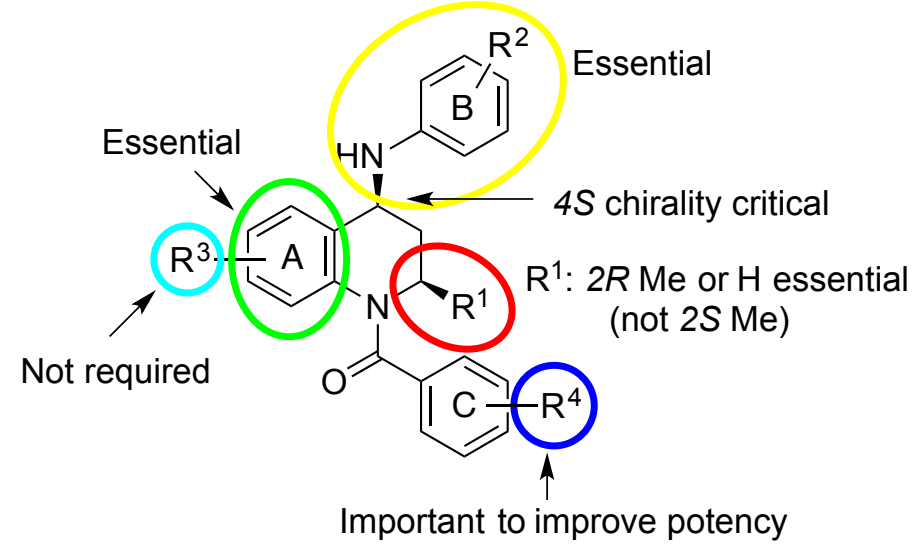

Fig. 4. Structural requirements of THQs for ecdysone agonist activity 


\section{Acknowledgements}

We thank Dr. Qing X. Li of the University of Hawaii for reviewing the manuscript. The Culex pipiens eggs were kindly provided by Sumitomo Chemical Co. Aedes albopictus cells (NIAS-AeAl-2) were obtained from the GeneBank of National Institute of Agrobiological Sciences (NIAS). This study was supported in part by the Ministry of Education, Culture, Sports, Science, and Technology of Japan (No. 25450070) and the $21^{\text {st }}$ century COE program for Innovative Food and Environmental Studies Pioneered by Entomomimetic Sciences. Dr. Toshiyuki Harada was a recipient of a Research Fellowship of the Japan Society for the Promotion of Science for Young Scientist.

\section{References and Notes}

1. Truman, J. W. Vitam Horm 2005, 73, 1.

2. $\quad$ Palli, S. R., Hormann R. E., Schlattner U., Lezzi M. Vitam Horm 2005, 73, 59.

3. Nakagawa, Y., Henrich V. C. The FEBS journal 2009, 276, 6128.

4. Morishita, C., Minakuchi C., Yokoi T., Takimoto S., Hosoda A., Akamatsu M., Tamura H., Nakagawa Y. J Pestic Sci in press

5. Billas, I. M., Iwema T., Garnier J. M., Mitschler A., Rochel N., Moras D. Nature 2003, 426, 91.

6. Carmichael, J. A., Lawrence M. C., Graham L. D., Pilling P. A., Epa V. C., Noyce L., Lovrecz G., Winkler D. A., Pawlak-Skrzecz A., Eaton R. E. et al J Biol Chem 2005, 280, 22258.

7. Iwema, T., Billas I. M., Beck Y., Bonneton F., Nierengarten H., Chaumot A., Richards G., Laudet V., Moras D. EMBO J 2007, 26, 3770. 
8. Browning, C., Martin E., Loch C., Wurtz J. M., Moras D., Stote R. H., Dejaegere A. P., Billas I. M. J Biol Chem 2007, 282, 32924.

9. HomePage http://wwwncbinlmnihgov/Structure/mmdb/mmdbsrvcgi?unid=3ixp (accessed on Nov 15, 2013)

10. Pener, M. P., Dhadialla T. S. In: Advances in Insect Physiology. Edited by Dhadialla TS. Oxford: Elsevier Ltd.; 2012: 1.

11. Ogura, T., Minakuchi C., Nakagawa Y., Smagghe G., Miyagawa H. FEBS J 2005, $272,4114$.

12. Dinan, L., Nakagawa Y., Hormann R. E. Adv Insect Physiol 2012, 43, 251.

13. Smith, H. C., Cavanaugh C. K., Friz J. L., Thompson C. S., Saggers J. A., Michelotti E. L., Garcia J., Tice C. M. Bioorg Med Chem Lett 2003, 13, 1943.

14. Palli, S. R., Tice C. M., Margam V. M., Clark A. M. Arch Insect Biochem Biophys 2005, 58, 234.

15. Soin, T., Swevers L., Kotzia G., Iatrou K., Janssen C. R., Rouge P., Harada T., Nakagawa Y., Smagghe G. Pest Manag Sci 2010, 66, 1215.

16. Funabashi, M., Iwakawa M., Yoshimur.J B Chem Soc Jpn 1969, 42, 2885.

17. Enomoto, N., Furukawa S., Ogasawara Y., Akano H., Kawamura Y., Yashima E., Okamoto Y. Anal Chem 1996, 68, 2798.

18. Nakagawa, Y., Minakuchi C., Takahashi K., Ueno T. Insect Biochem Mol Biol 2002, 32, 175.

19. Nakagawa, Y., Minakuchi C., Ueno T. Steroids 2000, 65, 537.

20. Sheldrick, G. M. Acta Crystallogr A 2008, 64, 112.

21. Compounds 1-4 were synthesized according to the reported methods. ${ }^{13}$ Briefly, ice-cold acetaldehyde ( $5 \mathrm{ml}, 157 \mathrm{mmol})$ was added drop-wise to a mixture of p-toluidine $(9.57 \mathrm{~g}, 89.3 \mathrm{mmol})$ and benzotriazole $(2.13 \mathrm{~g}, 17.9 \mathrm{mmol})$ in $90 \mathrm{ml}$ of $\mathrm{EtOH}$, and the mixture was stirred at room temperature for 4 days. After evaporating the solvent, the residue was purified by column chromatography (hexane: ethyl acetate $=4: 1)$ to give 2,6-dimethyl-4-(4-methylphenylamino)-1,2,3,4-tetrahydroquinoline (3.49 g, 13.1 mmol, $29 \%$ ) as a cis/trans mixture.

2,6-dimethyl-4-(4-methylphenylamino)-1,2,3,4-tetrahydroquinoline in THF and anhydrous pyridine were added drop-wise to a solution of 4-methylbenzoyl chloride 
$(1.14 \mathrm{ml}, 7.39 \mathrm{mmol})$ in anhydrous $\mathrm{THF}$ at $0^{\circ} \mathrm{C}$. The reaction mixture was warmed up to room temperature and stirred overnight. After adding $240 \mathrm{ml}$ of THF, the solution was washed with a saturated $\mathrm{NaHCO}_{3}$ aqueous solution and brine. The organic layer was dried over $\mathrm{MgSO}_{4}$ and concentrated. The residue was purified by column chromatography (hexane: ethyl acetate_=4:1) to give cis isomer compound 1 (270 mg (0.702 mmol), 19\%). mp: $185_{-}^{\circ} \mathrm{C}$. Anal. Calcd for $\mathrm{C}_{26} \mathrm{H}_{28} \mathrm{~N}_{2} \mathrm{O} \mathrm{C}, 81.21 ; \mathrm{H}$, 7.34. Found: C, 81.32; H, 7.56. Compound 2. mp: $183^{\circ} \mathrm{C}$. Anal. Calcd for $\mathrm{C}_{25} \mathrm{H}_{25} \mathrm{ClN}_{2} \mathrm{O}$ : C, 74.15; H, 6.22. Found C, 74.27; H, 6.36. Compound $3 \mathrm{mp}: 178_{-}^{\circ} \mathrm{C}$. Anal. Calcd for $\mathrm{C}_{23} \mathrm{H}_{19} \mathrm{ClF}_{2} \mathrm{~N}_{2} \mathrm{O}$ : C, 66.91; N, 6.79; H, 4.64. Found: C, 66.80; N, 6.82; H, 4.76. Compound 4: ${ }^{1} \mathrm{H}-\mathrm{NMR}\left(\mathrm{CDCl}_{3}, 400 \mathrm{MHz}\right) ; \delta(\mathrm{ppm}) 1.26(3 \mathrm{H}, \mathrm{d}, J=$ $6.4 \mathrm{~Hz}), 1.35(1 \mathrm{H}, \mathrm{m}), 2.81(1 \mathrm{H}, \mathrm{m}), 3.72(1 \mathrm{H}, \mathrm{br}), 4.33(1 \mathrm{H}, \mathrm{dd}, J=4.6,12.0 \mathrm{~Hz})$, $4.88(1 \mathrm{H}, \mathrm{m}), 6.48(1 \mathrm{H}, \mathrm{br}), 6.61(2 \mathrm{H}, \mathrm{m}), 6.68(1 \mathrm{H}, \mathrm{m}), 6.96(2 \mathrm{H}, \mathrm{m}), 7.06(1 \mathrm{H}, \mathrm{m})$, $7.12(2 \mathrm{H}, \mathrm{d}, J=6.6 \mathrm{~Hz}), 7.41(2 \mathrm{H}, \mathrm{d}, J=6.8 \mathrm{~Hz}) . \mathrm{mp}: 187^{\circ} \mathrm{C}$. Anal. Calcd for $\mathrm{C}_{23} \mathrm{H}_{19} \mathrm{BrF}_{2} \mathrm{~N}_{2} \mathrm{O}: \mathrm{C}, 60.41 ; \mathrm{N}, 6.13 ; \mathrm{H}, 4.19$. Found: C, 60.21; N, 6.17; H, 4.23.

22. Separation of enantiomers of compound $\mathbf{4}$ by chiral HPLC: The enantiomers were separated on a chiral HPLC column containing a silica gel bound to tris (3, 5-dimethylphenylcarbamate) derivatives of amylose (ADMPC) at a $2.0 \mathrm{ml} / \mathrm{min}$ flow rate at $40^{\circ} \mathrm{C}$ using hexane/ethanol (90/10). The analytes were detected by UV absorption at $254 \mathrm{~nm}$. An ADMPC-bound silica gel column was prepared according to the published method (Method-II in the report by Enomoto and coworkers ${ }^{17}$ ). The particle size of the column material was $5 \mu \mathrm{m}$ and was packed in a stainless steel tube $(250 \mathrm{~mm} \times 4.6 \mathrm{~mm})$. The retention times for each fraction are $4 \mathbf{a}(4.3 \mathrm{~min})$ and 4b (5.8 min), respectively. This HPLC fractionation was repeated 200 times, and all fractions were combined. Enantiomer excess (ee) was determined by the same method and found to be $>99 \%$. After evaporating the solvent, each compound was recrystallized from hexane-ethyl acetate to obtain $\mathbf{4 a}$ and $\mathbf{4 b}$ crystals. Melting points of these compounds were both $201^{\circ} \mathrm{C}$. The HRMS were 456.0647, 458.0631 (4a) and 456.0655, 458.0636 (4b), (Calcd. 456.0649, 458.0628). Optical rotations were $[\alpha]^{29}+443\left(c_{-}=0.040\right.$, ethanol $)$ for $4 \mathbf{a}$, and $[\alpha]^{29}-441\left(c_{-}=0.037\right.$, ethanol $)$ for $4 \mathbf{b}$. 
23. The crystals were mounted on a glass fiber, and measurements were made on a Rigaku RINT RAPID/R with graphite monochromated $\mathrm{Cu} K \alpha$ radiation $(\lambda=$ $1.5418 \AA$ ) at 243 K. All data were processed and corrected for Lorentz and polarization effects. Intensity data within $2 \theta_{-} \leqq \ldots 136.4^{\circ}$ were measured using an imaging plate area detector. The structure was solved by direct method using the SHELXS-97 program $^{20}$. Positional parameters of non-H atoms were refined by full-matrix least squares using the SHELXL-97 $\operatorname{program}^{20}$. All non-hydrogen atoms were refined with anisotropic thermal parameters. Hydrogen atoms were placed in geometrically idealized positions and standard riding atoms. Crystal data, data collection parameters, and results of the analyses for compound $\mathbf{1}$ and $\mathbf{2}$ are listed in Supplement Table S2 and deposited under the designations CCDC 984530 (4a) and 984531 (4b). Crystal data for compounds 1 and 2 were also deposited under designations 984528 and 984529 , respectively.

24. The eggs of the mosquito Culex pipiens pallens were kindly provided by Sumitomo Chemical Company (Hyogo, Japan), and reared to the $2^{\text {nd }}$ instar in the laboratory using a $300 \mathrm{~cm}^{2}$ (approx. $5 \mathrm{~cm}$ water depth) tank. Three tablets of Ebios (Asahi Food and Health) were added under conditions of a long-day photo period (16 h light: $8 \mathrm{~h}$ dark). Twenty larvae grown for two days after hatching and were transferred to a paper cup containing $30 \mathrm{ml}$ of water and a small amount of Ebios. To this was added $10 \mu \mathrm{l}$ of DMSO solution with varying concentrations of the test compounds. After rearing for three additional days, the mortality of the mosquitos was evaluated. In each experiment, DMSO was used as a negative control, and tebufenozide treatment $(33 \mu \mathrm{M})$ was used as a positive control (100\% mortality). The median lethal concentration $\left(\mathrm{LC}_{50}\right)$ was evaluated from the concentration-response curves, and the reciprocal logarithm of $\mathrm{LC}_{50}\left(\mathrm{pLC}_{50}\right)$ was used as the index of larvicidal activity.

25. The binding assay procedure is the same as that reported previously ${ }^{18,19}$. Insect cells of the forest day mosquito Aedes albopictus (NIAS-AeAl-2) were obtained from the 
National Institute of Agrobiological Sciences (NIAS) GeneBank

(http://www.gene.affrc.go.jp/index_en.php). AeAl cells were cultured at $25^{\circ} \mathrm{C}$ in $25-\mathrm{cm}^{3}$ tissue culture flasks containing approximately $5 \mathrm{ml}$ of the culture medium EX-Cell 401 (SAFC Biosciences) supplemented with 10\% fetal bovine serum (FBS). Cell suspensions $(400 \mu \mathrm{l})$ were added to disposable glass tubes $(12 \mathrm{~mm} \times 75 \mathrm{~mm})$ containing $1 \_\mu l$ of the test compound in a DMSO solution at the bottom of the glass tube. Two microliters (ca. $60000 \mathrm{dpm})$ of $\left[{ }^{3} \mathrm{H}\right]$ PonA (140 Ci/mmol; American Radiolabeled Chemicals, Inc., St Louis, MO, USA) solution diluted with 70\% ethanol was then added at $1-\mathrm{min}$ intervals and incubated at $25^{\circ} \mathrm{C}$. After $30 \mathrm{~min}$ of incubation, $3 \mathrm{ml}$ of water was added to the tubes. The contents were immediately filtered through glass filters (GF-75, ф25 mm; ADVANTEC, Tokyo, Japan) and washed two times with $3 \mathrm{ml}$ of water. The filters were dried under an infrared lamp, and placed into LSC vials. The amount of radioactivity collected on the filters was measured in $3 \mathrm{ml}$ of Aquasol-2 (Packard Instrument Co., Meriden, CT, USA) using an Aloka LSC-5000 counter (Aloka Co., Ltd, Tokyo, Japan). The concentration required to give $50 \%$ inhibition of the binding of $\left[{ }^{3} \mathrm{H}\right] \mathrm{PonA}\left(\mathrm{IC}_{50}, \mathrm{M}\right)$ was determined from the concentration-response curve, and the reciprocal logarithm of $\mathrm{IC}_{50}\left(\mathrm{pIC}_{50}\right)$ was used as the index of binding activity. 
Table S1. X-ray crystallographic data for enantiomers $\mathbf{1}$ (cis) and $\mathbf{2}$ (cis)

\begin{tabular}{|c|c|c|}
\hline & $1(c i s)$ & $2(c i s)$ \\
\hline Empirical formula & $\mathrm{C}_{26} \mathrm{H}_{28} \mathrm{~N}_{2} \mathrm{O}$ & $\mathrm{C}_{25} \mathrm{H}_{25} \mathrm{~N}_{2} \mathrm{OCl}$ \\
\hline Formula weight & 384.52 & 404.94 \\
\hline Crystal system & Triclinic & Triclinic \\
\hline Space group & P1 & P1 (\#2) \\
\hline $\mathrm{a}(\AA)$ & $9.614(2)$ & $9.602(2)$ \\
\hline $\mathrm{b}(\AA)$ & $14.574(3)$ & $14.447(3)$ \\
\hline c $(\AA)$ & $16.551(3)$ & $16.622(3)$ \\
\hline$\alpha(\operatorname{deg})$ & $93.57(1)$ & $93.47(1)$ \\
\hline$\beta(\operatorname{deg})$ & $93.72(1)$ & $95.23(1)$ \\
\hline$\gamma(\mathrm{deg})$ & $107.20(1)$ & $108.37(1)$ \\
\hline$V\left(\AA^{3}\right)$ & $2202.7(7)$ & $2169.5(7)$ \\
\hline$Z, D_{\text {calc }}\left(\mathrm{g} / \mathrm{cm}^{3}\right)$ & $4,1.159$ & $4,1.240$ \\
\hline$F(000)$ & 824.00 & 856.00 \\
\hline$\mu(\mathrm{Cu} \mathrm{K} \alpha)\left(\mathrm{mm}^{-1}\right)$ & 0.546 & 1.688 \\
\hline$T(\mathrm{~K})$ & 253 & 253 \\
\hline $\begin{array}{c}\text { No. obsd } \\
(I>2.00 \sigma(I))\end{array}$ & 6216 & 9700 \\
\hline No. parameters & 639 & 588 \\
\hline$R_{1}, \mathrm{w} R_{2}$ & $0.039,0.104$ & $0.048,0.123$ \\
\hline GOF & 0.862 & 1.005 \\
\hline
\end{tabular}


Table S2. X-ray crystallographic data for enantiomers 9a and $9 \mathbf{b}$

\begin{tabular}{ccc}
\hline & $\mathbf{4 . 3} \mathbf{~ m i n}$ & $\mathbf{5 . 8} \mathbf{~ m i n}$ \\
\cline { 2 - 3 } & $\mathbf{9 a}$ & $\mathbf{9 b}$ \\
\hline Empirical formula & $\mathrm{C}_{23} \mathrm{H}_{19} \mathrm{BrF}_{2} \mathrm{~N}_{2} \mathrm{O}$ & $\mathrm{C}_{23} \mathrm{H}_{19} \mathrm{BrF}_{2} \mathrm{~N}_{2} \mathrm{O}$ \\
Formula weight & 457.32 & 457.32 \\
Crystal system & orthorhombic & orthorhombic \\
Space group & $\mathrm{P} 2{ }_{1}{ }_{1} 2_{1}(\# 19)$ & $\mathrm{P} 2_{1} 2{ }_{1} 2_{1}(\# 19)$ \\
$\mathrm{a}(\AA)$ & $7.726(1)$ & $7.7240(2)$ \\
$\mathrm{b}(\AA)$ & $11.425(1)$ & $11.423(3)$ \\
$\mathrm{c}(\AA)$ & $23.284(2)$ & $23.288(5)$ \\
$V(\AA)$ & $2055.4(3)$ & $2054.8(8)$ \\
$Z, D_{\text {calc }}\left(\mathrm{g} / \mathrm{cm}^{3}\right)$ & $4,1.478$ & $4,1.478$ \\
$F(000)$ & 928.00 & 928.00 \\
$\mu(\mathrm{Cu} \mathrm{K} \alpha)\left(\mathrm{mm}^{-1}\right)$ & 3.024 & 3.025 \\
$T(\mathrm{~K})$ & 243 & 243 \\
no. obsd & 3506 & 3338 \\
$(I>2.00 \sigma(I))$ & & \\
no. parameters & 265 & 265 \\
$R_{l}, \mathrm{w} R_{2}$ & $0.040,0.156$ & $0.043,0.145$ \\
Flack parameter & $0.01(2)$ & $0.01(2)$ \\
$\mathrm{GOF}$ & 1.300 & 1.031
\end{tabular}

